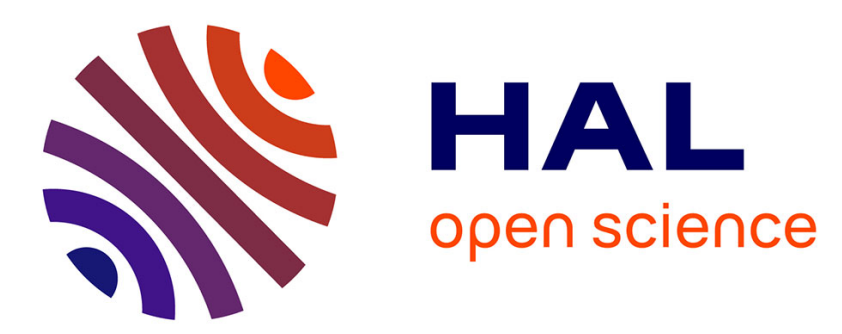

\title{
High temperature oxidation of two- and three-dimensional hafnium carbide and silicon carbide coatings
}

C. Verdon, O. Szwedek, A. Allemand, S. Jacques, Y. Le Petitcorps, P. David

\section{- To cite this version:}

C. Verdon, O. Szwedek, A. Allemand, S. Jacques, Y. Le Petitcorps, et al.. High temperature oxidation of two- and three-dimensional hafnium carbide and silicon carbide coatings. Journal of the European Ceramic Society, 2014, 34 (4), pp.879-887. 10.1016/j.jeurceramsoc.2013.10.019 . hal-01617484

\author{
HAL Id: hal-01617484 \\ https://hal.science/hal-01617484
}

Submitted on 16 Oct 2017

HAL is a multi-disciplinary open access archive for the deposit and dissemination of scientific research documents, whether they are published or not. The documents may come from teaching and research institutions in France or abroad, or from public or private research centers.
L'archive ouverte pluridisciplinaire HAL, est destinée au dépôt et à la diffusion de documents scientifiques de niveau recherche, publiés ou non, émanant des établissements d'enseignement et de recherche français ou étrangers, des laboratoires publics ou privés. 


\title{
High temperature oxidation of two- and three-dimensional hafnium carbide and silicon carbide coatings
}

\author{
By

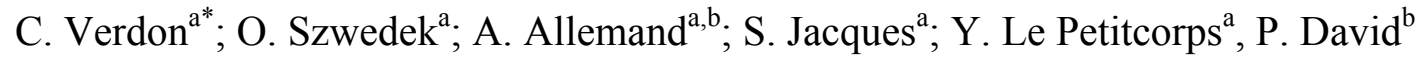 \\ ${ }^{a}$ Université Bordeaux, LCTS, UMR5801, F-33600 Pessac France \\ ${ }^{b}$ CEA, DAM, Le Ripault F-37260 Monts France
}

Journal of the European Ceramic Society, 34(4), 879-887 (2014)

DOI : https://doi.org/10.1016/j.jeurceramsoc.2013.10.019

http://www.sciencedirect.com/science/article/pii/S0955221913004792 


\title{
High temperature oxidation of two- and three-dimensional hafnium carbide and silicon carbide coatings
}

\author{
C. Verdon ${ }^{a^{*}}$; O. Szwedek ${ }^{\text {a }}$ A. Allemand ${ }^{\mathrm{a}, \mathrm{b}} ;$ S. Jacques ${ }^{\mathrm{a}} ;$ Y. Le Petitcorps ${ }^{\mathrm{a}}$, P. David ${ }^{\mathrm{b}}$ \\ ${ }^{a}$ Université Bordeaux, LCTS, UMR5801, F-33600 Pessac France \\ ${ }^{b}$ CEA, DAM, Le Ripault F-37260 Monts France \\ *verdon@lcts.u-bordeaux1.fr \\ Phone : +335 56844730 \\ Fax: +33556841225
}

Keywords UHTC; oxidation; carbides; refractories; Hafnium

\begin{abstract}
The difficulty in using above $2000^{\circ} \mathrm{C}$ in an oxidizing atmosphere $C / C$ composites as structural components is their poor life time. The solution proposed here consisted in combining two refractory carbides, hafnium and silicon carbides, in coating with a complex architecture, named a three dimensional coating, over a $C / C$ substrate. Such a coating protects the $C / C$ composite at $2050^{\circ} \mathrm{C}$ under air. The oxidation of the coating leads to the formation of a $\mathrm{Si}_{x} \mathrm{O}_{y} \mathrm{Hf}_{z}$ hafnium-containing silicate liquid, combined with $\mathrm{HfO}_{2(s)}$. This liquid limits oxygen diffusion more than pure $\mathrm{SiO}_{2}$ does, so it is a better protection against oxidation. Furthermore, $\mathrm{HfO}_{2(s)}$ acts as a grip holding $\mathrm{Si}_{x} \mathrm{O}_{y} \mathrm{Hf}_{z}$ in place. From these results, an oxidation mechanism is proposed and discussed.
\end{abstract}

\section{Introduction}

$\mathrm{C} / \mathrm{C}$ composites (carbon fibers embedded in carbon matrices) exhibit a poor lifetime under an oxidizing atmosphere; the carbon fiber starts to be oxidized under air at a temperature of $400^{\circ} \mathrm{C}$ [1]. In order to protect composites from oxidation, many coatings made of Ultra High Temperature Ceramics (UHTCs) have been tested. It is known that they can resist to extreme heat flux and high mechanical stresses [2]. For example, Clougherty et al. have studied oxidation of diborides $\mathrm{HfB}_{2}, \mathrm{ZrB}_{2} \mathrm{TiB}_{2}$ and a mixture of $\mathrm{HfB}_{2}-\mathrm{SiC}$ [3]. The oxidation mechanism model of these coatings have been studied by Parthasarathy et al. [4] who proposed a mechanistic model that simulates the oxidation behavior of the diborides in the temperature range of $1000^{\circ} \mathrm{C}$ to $1800^{\circ} \mathrm{C}$. Among the studied carbide-based coatings, an $\mathrm{HfC} / \mathrm{SiC}$ dual layer developed by Wunder et al. has shown promising oxidation protection for PyC-coated $\mathrm{C} / \mathrm{C}$ composites at temperatures up to $1450^{\circ} \mathrm{C}$ [5]. Besides, Baklanova et al. highlighted the fact that $\mathrm{HfC} / \mathrm{SiC}$-coated carbon fibers exhibit a higher oxidation resistance at $2000^{\circ} \mathrm{C}$ than the initial $\mathrm{HfC}$-coated carbon fibers [6]. Wang et al. have determined that $\mathrm{SiC} / \mathrm{HfC} / \mathrm{SiC}$ is an interesting coating to protect carbon/carbon composites with a mass loss of only $2.3 \%$ after oxidation at $1500^{\circ} \mathrm{C}$. They also have characterized a stable glassy phase composed by $\mathrm{HfSiO}_{4}$ which could protect $\mathrm{C} / \mathrm{C}$ composites [7].

In the present work, two carbides were selected. SiC has been used in many works; it allows protection against oxidation until $1650^{\circ} \mathrm{C}$ by forming a $\mathrm{SiO}_{2}$ layer [8]. It is the best diffusion barrier against oxidation below $1400^{\circ} \mathrm{C}$ [1]. But, above $1650^{\circ} \mathrm{C}$ under air the oxidation becomes active and all the protection is lost. In spite of a high melting point $\left(3890^{\circ} \mathrm{C}\right), \mathrm{HfC}$ is actively oxidized at low temperature, from $400-500^{\circ} \mathrm{C}$, forming porous $\mathrm{HfO}_{2}$. Its oxidation behavior has been studied by Shimada et al. [9]. Although not protective, this oxide has the 
advantage of being refractory with a melting point of $2810^{\circ} \mathrm{C}$ and has a lower vapor pressure than $\mathrm{SiO}_{2}$ [4]. The aim of the present study was to combine theses two carbides to find a synergetic effect: a refractory coating that allows a good oxidation resistance. Two kinds of samples, monolithic $\mathrm{HfC} / \mathrm{SiC}$ sintered samples and $\mathrm{C} / \mathrm{C}$ composites with $(\mathrm{HfC} / \mathrm{SiC})_{\mathrm{n}}$ multilayer coatings, were prepared [10] [11] and then characterized after high temperature oxidation. This characterization of the oxidized samples allowed us to propose an oxidation mechanism.

\section{Experimental procedure}

2.1. Monolithic sample

The monolithic freestanding sample (named sample A, Table 1) was prepared by following two steps.

Table 1: Sample characteristics overview

\begin{tabular}{llll} 
& Sample A & Sample B & Sample C \\
\hline $\begin{array}{l}\text { Sample kind } \\
\text { Sample }\end{array}$ & Monolithic & 2D $(10$ layers $)$ & 3D $+2 \mathrm{D}(10$ layers $)$ \\
composition & HfC/SiC & C/C substrate & C/C substrate \\
Way of synthesis & FBCVD + SPS & CVD $(\mathrm{HfC} / \mathrm{SiC})_{5}$ & $+(\mathrm{HfC} / \mathrm{SiC})_{5}$ \\
\end{tabular}

HfC powder with a $\mathrm{d}_{50}=35^{\circ} \mu \mathrm{m}$, was first coated with $1 \mu \mathrm{m}$ of $\mathrm{SiC}$ by fluidized bed chemical vapor deposition (FBCVD). This work was supplied externally to Lifco industry. Then this core-shell powder was sintered by spark plasma sintering (SPS). Sintering parameters were: temperature of $1950^{\circ} \mathrm{C}$, pressure of $18 \mathrm{MPa}$ and dwell time of 5 minutes, following cycles presented in Fig. 1.

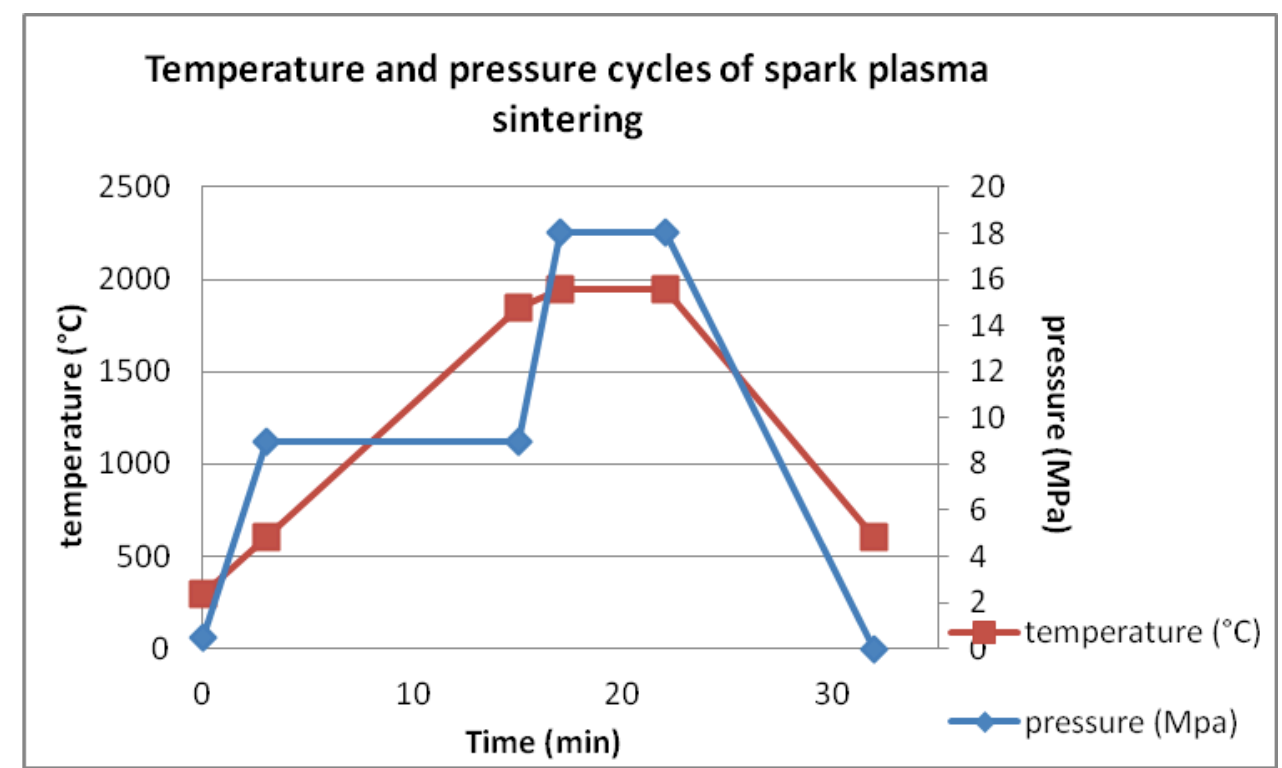

Fig. 1: pressure and temperature cycles of spark plasma sintering

The machine was a Dr Sinter 2080 from Syntex (Japan). The final sample was a cylinder with a diameter of $12 \mathrm{~mm}$ and a thickness of $6 \mathrm{~mm}$.

2.2. Multilayered coating made by CVD 
The other kinds of samples, (sample B and sample $\mathrm{C}$, Table 1) consisted in $(\mathrm{SiC} / \mathrm{HfC})_{\mathrm{n}}$ multilayer coatings over $\mathrm{C} / \mathrm{C}$ substrates by low pressure Chemical Vapor Deposition (CVD) at $1000^{\circ} \mathrm{C}$ and $5 \mathrm{kPa}$. Sample $\mathrm{B}$ and $\mathrm{C}$ have same size as sample A. The device used was composed of a hot-wall CVD reactor and a chlorinating device. $\mathrm{HCl}_{(\mathrm{g})}$ reacted at $700^{\circ} \mathrm{C}$ with metallic $\mathrm{Hf}_{(\mathrm{s})}$ to form $\mathrm{HfCl}_{4(\mathrm{~g})}$ in the chlorinating device. The hafnium metal was an electrolytic grade $\mathrm{Hf}_{(\mathrm{s})}$ supplied by Areva. $\mathrm{HfCl}_{4(\mathrm{~g})}$ precursor was simultaneously injected with argon as a carrier gas and reacts with $\mathrm{CH}_{4(\mathrm{~g})}$ and $\mathrm{H}_{2(\mathrm{~g})}$ in the CVD reactor to give HfC coating. The $\mathrm{SiC}$ layers were classically made from methyltrichlorosilane and hydrogen. The MTS was supplied by Sigma Aldrich and its purity was superior to $97 \%$.

Sample B consisted of a classical bi-dimensional coating made of ten alternated layers of $\mathrm{SiC}$ and HfC, according to the Kaplan's patent [12]. A structure scheme, corresponding to the five first layers, is presented by Fig. 2. The five last layers are identical to the five first one.
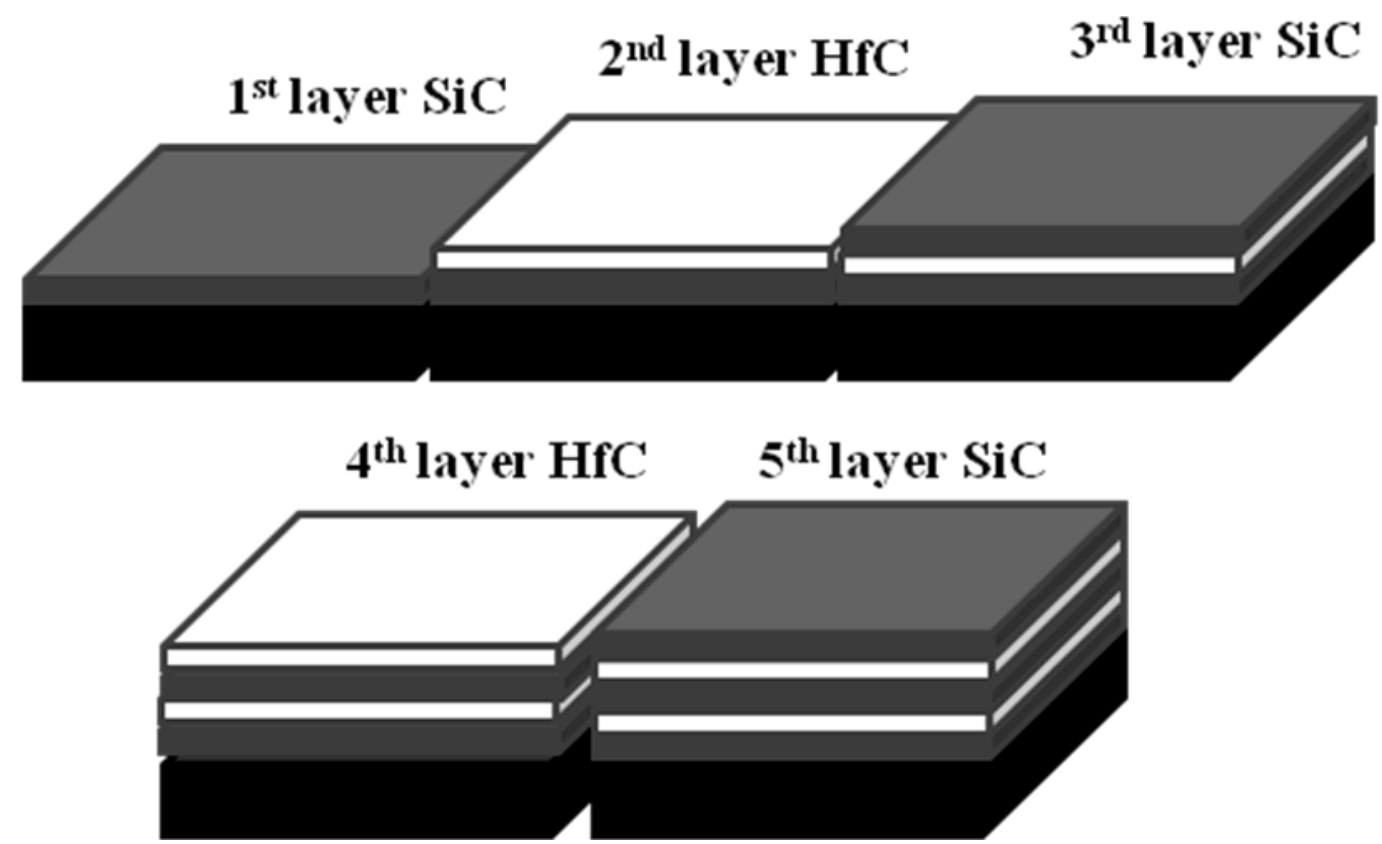

Fig. 2: structure scheme of the 5 first layers of sample B corresponding to $2 D$ structure coating.

Sample $\mathrm{C}$ consisted of five alternated layers of $\mathrm{HfC}$ and $\mathrm{SiC}$ with a three-dimensional arrangement and another five alternated layers of $\mathrm{HfC}$ and $\mathrm{SiC}$ with a two-dimensional arrangement, according to our patent [11]. A structure scheme corresponding to the five first layers formation of the 3D structure is presented Fig. 3. The five last layers are identical to the five first sample B layers. 

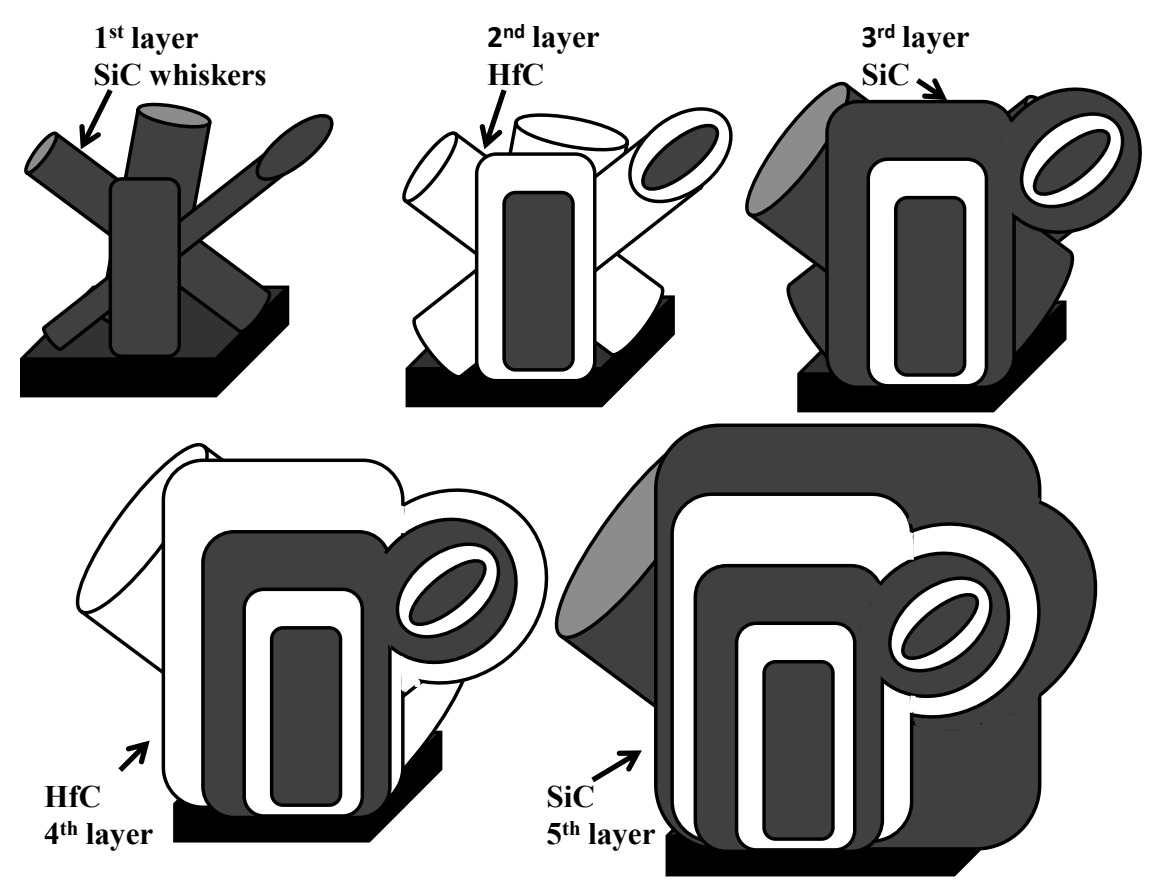

Fig. 3: Structure scheme of the 5 first layers of sample $C$ corresponding to 3D structure coating.

\subsection{Oxidation test}

The samples were oxidized under air in an arc image furnace at the CEA/Cesta center (Bordeaux, France). The furnace is composed by six Xenon arc lamps. These lamps are placed in the first focus of elliptical reflectors in order to concentrate emitted radiation at the second focus. The second focus of each reflector coincides in one place, corresponding to sample position. It allows adding six lamps energy on surface sample. The temperature of the center of the samples measured by a thermocouple reached $1600^{\circ} \mathrm{C}$ in 50 seconds and finally $2000^{\circ} \mathrm{C}$ in 200 seconds. Then samples are kept few seconds at $2000^{\circ} \mathrm{C}$ Seven samples were oxidized. The temperature profile is presented by the Fig. 4. This time and temperature of oxidation test correspond to sample B coating destruction. The center of the surface sample was the most affected area due to a temperature gradient between the centre and the side of surface sample.

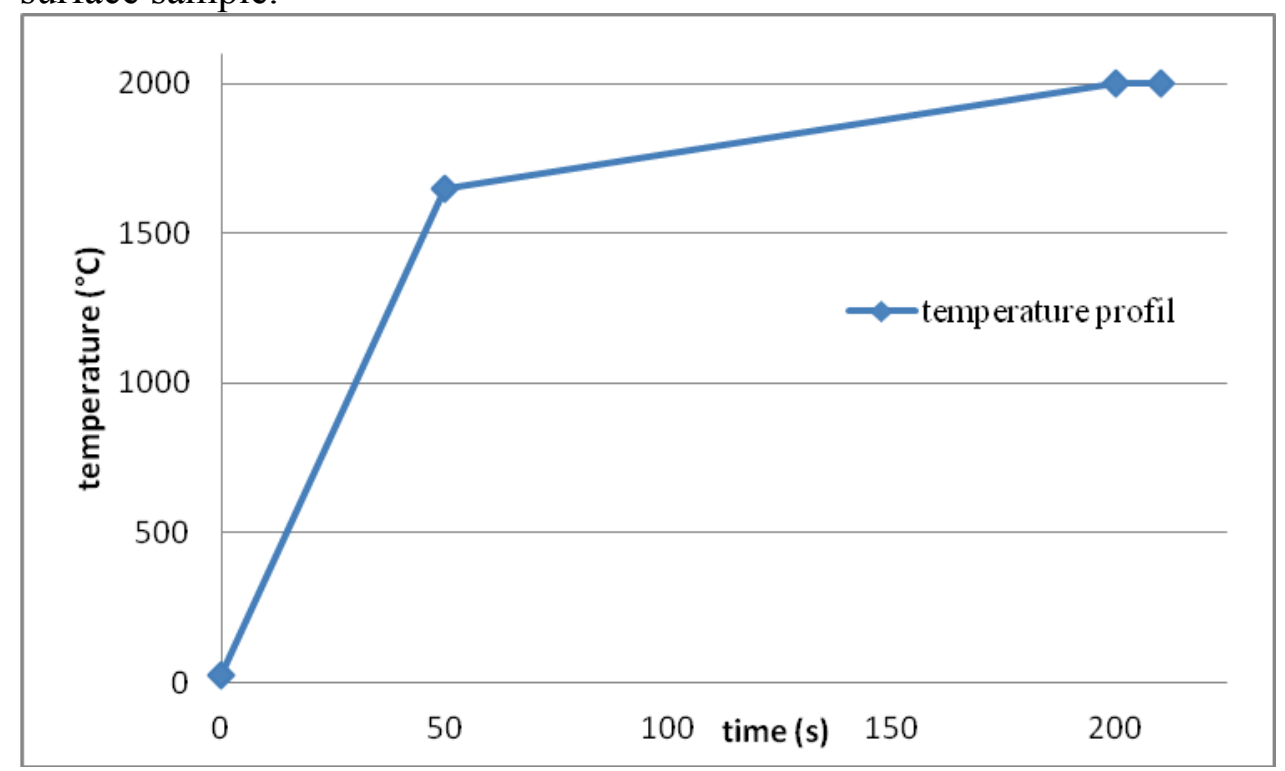

Fig. 4: temperature profile applied for the oxidation test. 


\subsection{Characterization}

The crystal structure of the sample surface was identified by X-ray diffraction (XRD) with a Diffractometer D8 advance Bruker $(\mathrm{CuK} \alpha)$. Before and after oxidation test, specimens were mounted in resin, cut and polished in order to carry out morphological observation by scanning electron microscopy (SEM) with a SEM FEI Quanta 400 FEG using backscattered electron (BSE) and secondary electron (SE) detectors under an accelerating voltage less than $20 \mathrm{kV}$. Qualitative chemical analyses were also performed in the microscope by energy dispersive X-ray spectroscopy (EDS). The composition of each layer after oxidation was determined more precisely by electron probe microanalysis (EPMA) with an EPMA CAMECA SX100. Raman spectroscopy analyses was realized with a Horiba Jobin-Yvon, Labram HR spectrometer $\left(\lambda_{\mathrm{He}-\mathrm{Ne}}=632.8 \mathrm{~nm}\right)$

\section{Results}

\subsection{Monolithic sample}

The Fig. 5 A) presents an HfC particle before FBCVD. The Fig. 5 B) corresponds to a back scattered electron picture of HfC coated powder, coating is uniform almost every particles are coated. Coated particles are grey and uncoated particles are white.

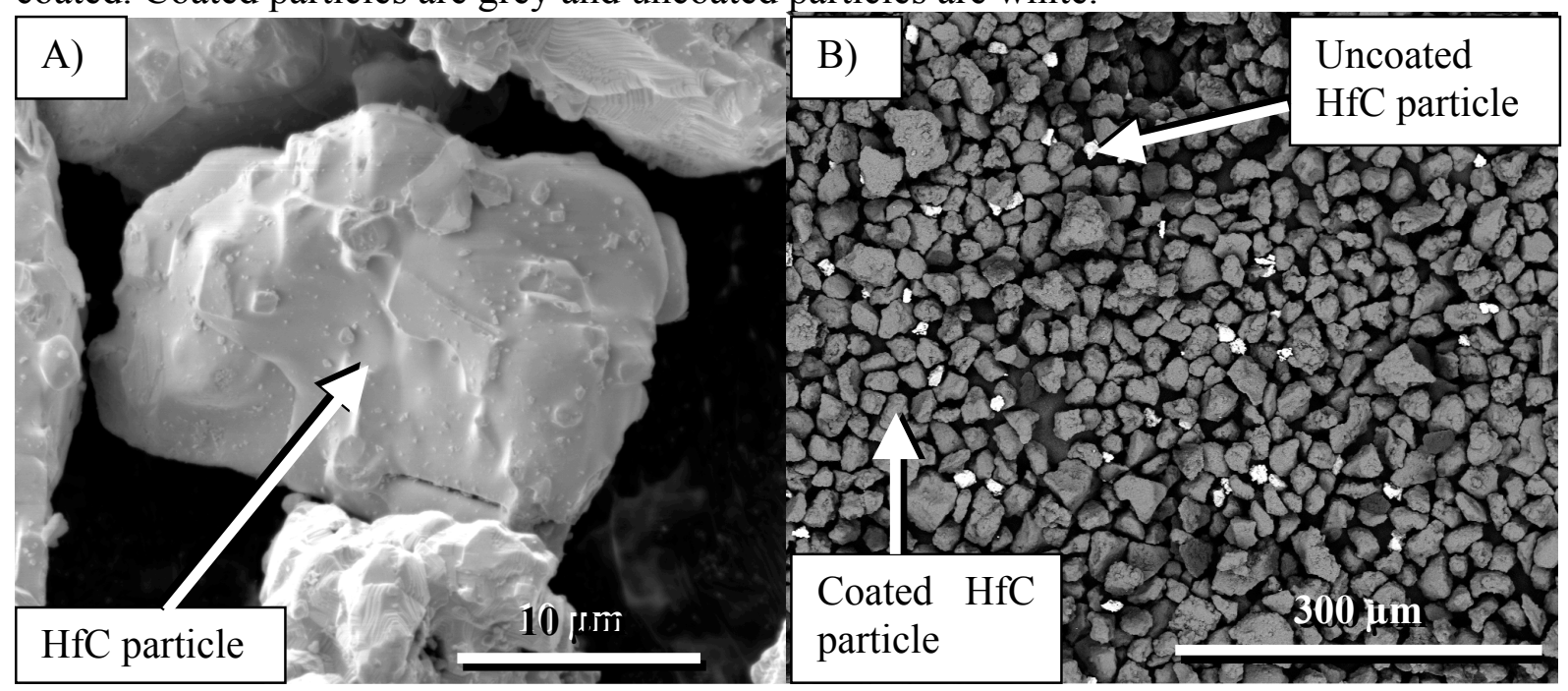

Fig. 5: A) morphology of the HfC particle before FBCVD. B) Back scattered electron of HfC powder coated by $\mathrm{SiC}$.

During spark plasma sintering bonding between particles of core-shell powder is created. Particles are welded together into a monolithic sample. Fig. 6 presents a polish cross section of a monolithic sample before oxidation (sample A). A homogeneous SiC layer is visible around particles. The sample polishing (made by cross-polisher) allows particles component to refill a part of porosities between particles and create a thin white layer inside it. 


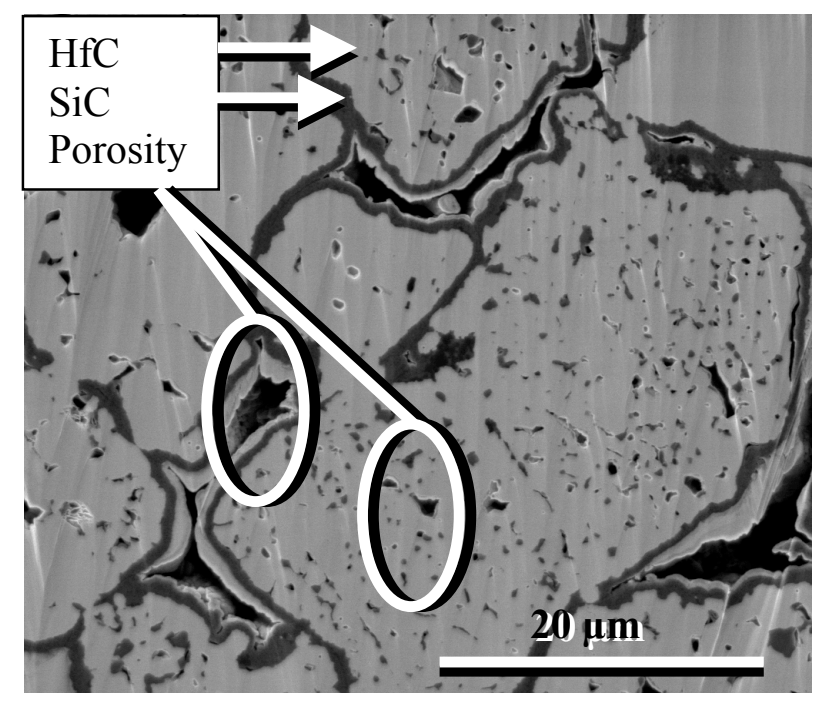

Fig. 6: polished section of monolithic sample observed by SEM.

Sample A is the most convenient to investigate the oxidation behavior because its important thickness allows all the oxidation steps to be separated. The sample has not been affected in the bulk by oxidation. After oxidation, following the path exhibited in paragraph 2.3 oxidation test, the sample is studied by XRD.

The analysis of the sample surface gives a pattern typical of crystallized oxide $\mathrm{HfO}_{2(\mathrm{~s})}$ corresponding to the JCPDS card $\mathrm{N}^{\circ} 04-005-4474$ (Fig. 7). $\mathrm{HfO}_{2}$ is the only detected phase. The pattern of the untouched material is not visible under this thick oxide seals. 


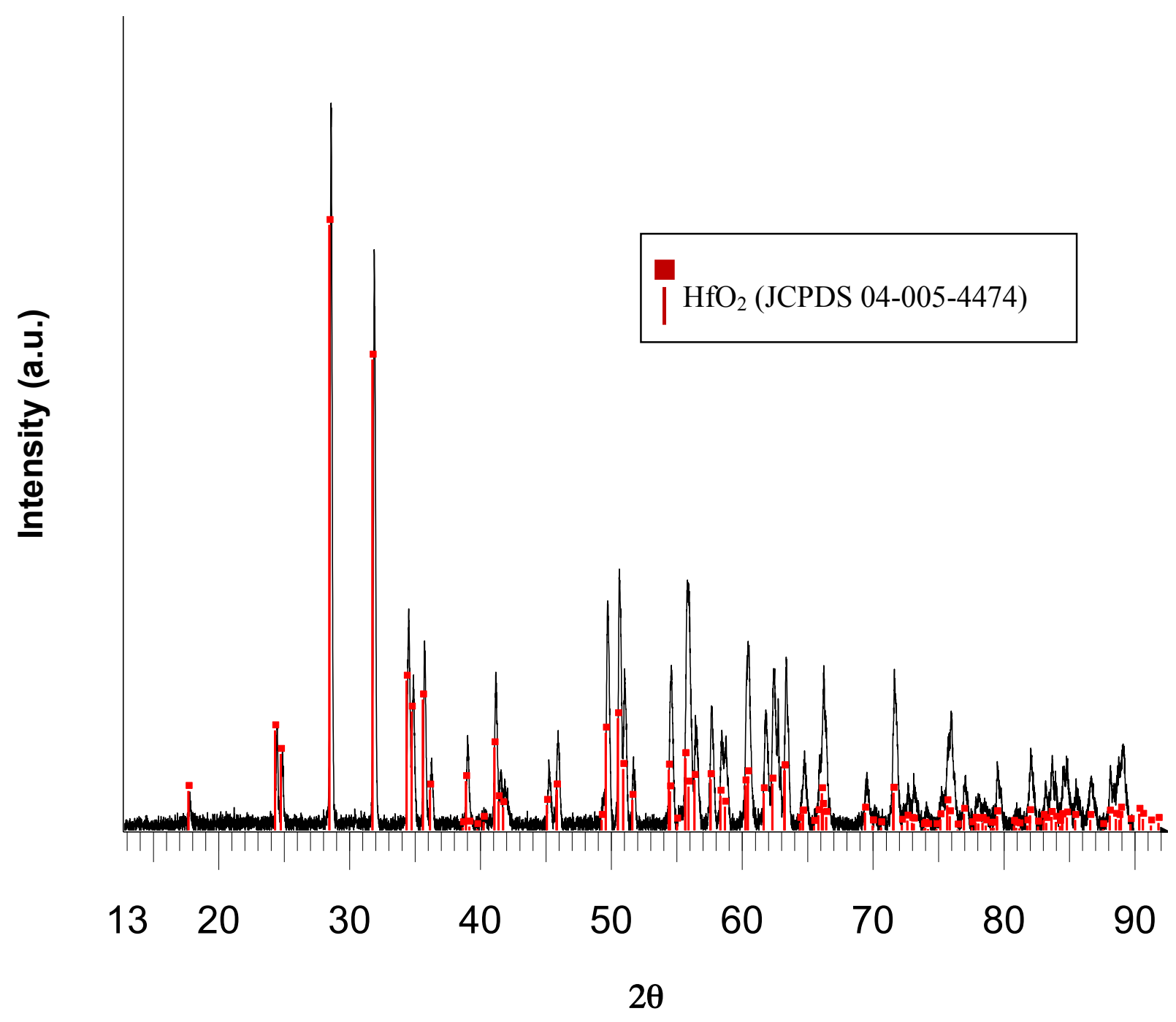

Fig. 7: XRD pattern of sample A surface oxidized.

The sample is composed of 3 areas observed by scanning electron microscopy in Fig. 8 a). Area 1 is undamaged and exhibits a thickness of $59 \mathrm{~mm}$, Fig. $8 \mathrm{~b}$ ). It is composed of HfC grains with $\mathrm{SiC}$ at $\mathrm{HfC}$ grains boundary, no change of grains sizes can be highlighted. Few porosities are visible. Area 2, Fig. $8 \mathrm{c}$ ) is highly porous and is around $100 \mu \mathrm{m}$ thick. Silicon could not be found in Area 2. Area 3, at the outer surface, is composed of an oxide skeleton in a glassy continuous phase and is around $250 \mu \mathrm{m}$ thick, Fig $8 \mathrm{~d}$ ). 


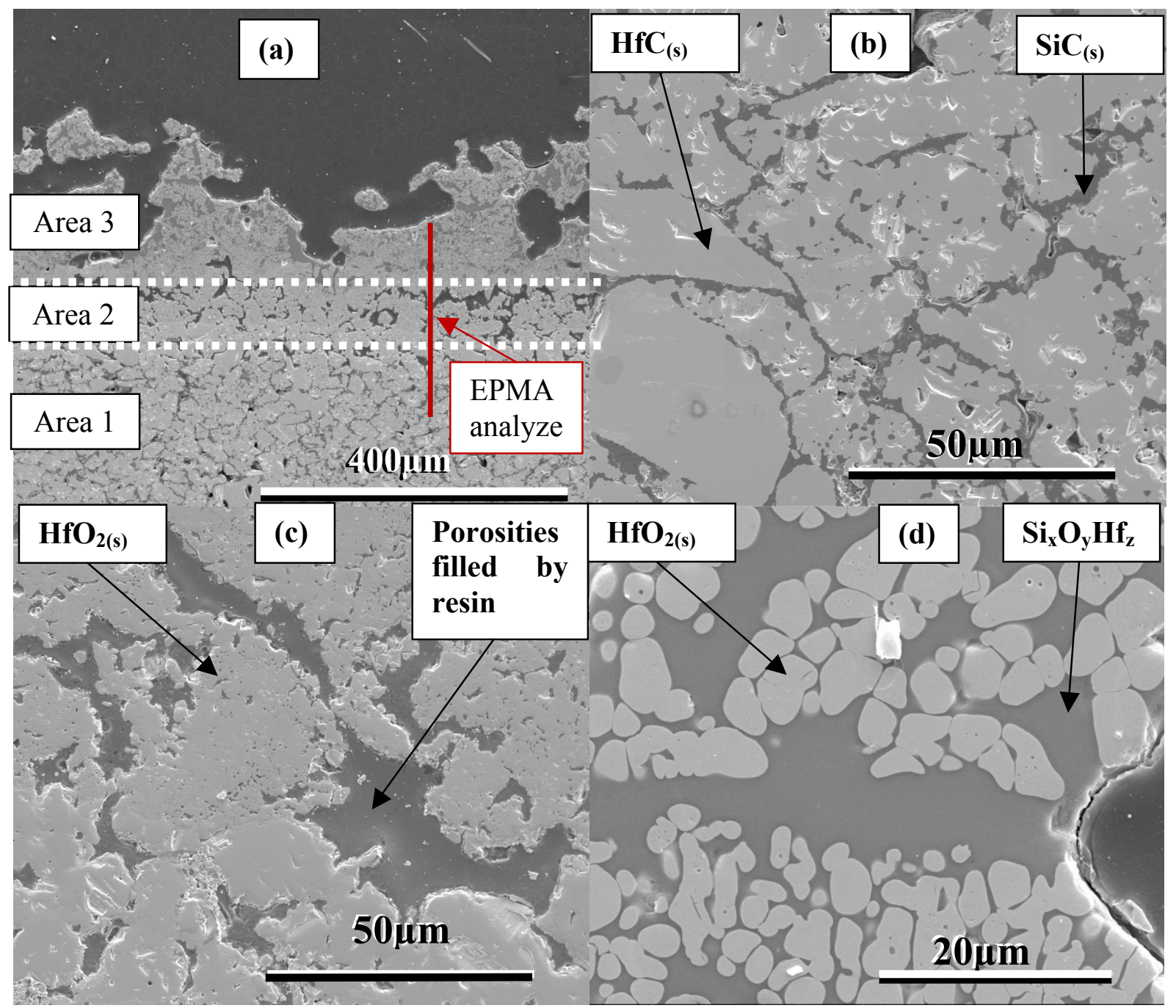

Fig. 8: SE SEM observation of sample $A$ after oxidation at $2000^{\circ} \mathrm{C}$ and quenched under air: overview image with the 3 areas that compose this sample (a), example of enlarged view of area 1 composed by 2 carbides (b), example of enlarge view of area 2 composed by $\mathrm{HfO}_{2(\mathrm{~s})}$ (c), example of enlarge view of area 3 composed of two oxides $\left(\mathrm{HfO}_{2}\right.$ and $\left.\mathrm{Si}_{\mathrm{x}} \mathrm{O}_{\mathrm{y}} \mathrm{Hf}_{\mathrm{z}}\right)(\mathrm{d})$.

EDS analyses show that the glassy phase consists mainly of silicon with oxygen and some hafnium (less than $5 \%$ atomic) according to the formula $\mathrm{Si}_{\mathrm{x}} \mathrm{O}_{\mathrm{y}} \mathrm{Hf}_{\mathrm{z}}$. The oxide skeleton is composed of hafnium and oxygen in proportion of $\mathrm{HfO}_{2}$, confirmed by EPMA. The oxidation area total thickness is around $350 \mu \mathrm{m}$.

Fig. ${ }^{\circ} 9$ corresponds to component quantities observed during EPMA analyze. The Table II lists average quantity of element detected in each area. The hafnium atomic composition determined by EPMA is quasi-constant on the entire sample (Fig. 9 and Table II) aside from holes and particle boundary. The silicon is present in areas 1 and 3; area 2 is silicon-free. The atomic percent of carbon decreases from area 1 to area 3. In area 2, carbon peaks correspond to porosity filed with carbon resin. In area 3, carbon is no more detected. In reverse, the oxygen atomic content increases from the inside to the outside of the sample (Fig. 9 and Table II). 


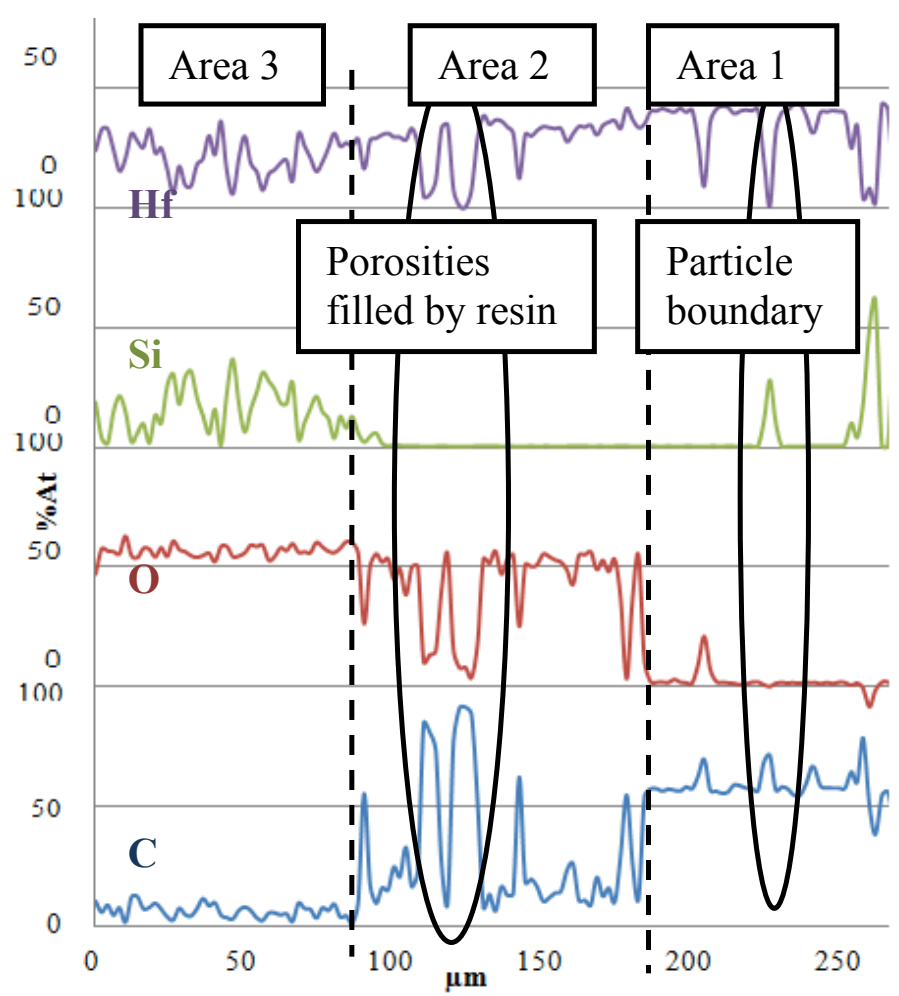

Fig. 9: EPMA analyses of sample A after oxidation.

Table II: average composition of sample areas.

\begin{tabular}{|lrrr|}
\hline \multicolumn{4}{c}{ average composition (\%at) } \\
\hline element & area 3 & area 2 & area 1 \\
\hline Hf & 21,1 & 27,6 & 33,2 \\
\hline Si & 15,2 & 0,5 & 6,7 \\
\hline O & 56,6 & 41,4 & 2,1 \\
\hline C & 7,0 & 30,5 & 58,5 \\
\hline
\end{tabular}

The compositions of the three areas can be deduced from this analysis. Area 1 is a non affected part composed of $\mathrm{HfC} / \mathrm{SiC}$ grains. Area 2 is made of porous $\mathrm{HfO}_{2(\mathrm{~s})}$. Area 3 is composed of $\mathrm{HfO}_{2(\mathrm{~s})}$ skeleton combined with amorphous $\mathrm{Si}_{\mathrm{x}} \mathrm{O}_{\mathrm{y}} \mathrm{Hf}_{\mathrm{z}}$ (Fig. 8 d). The $\mathrm{Si}_{\mathrm{x}} \mathrm{O}_{\mathrm{y}} \mathrm{Hf}_{\mathrm{z}}$ glass is, of course, not detected by XRD because of its amorphous structure (Fig. 7).

The microstructure of the oxidized sample A exhibits the presence of holes in area 3 which results from gas formation in large quantities (Fig. 10) and accumulation. 


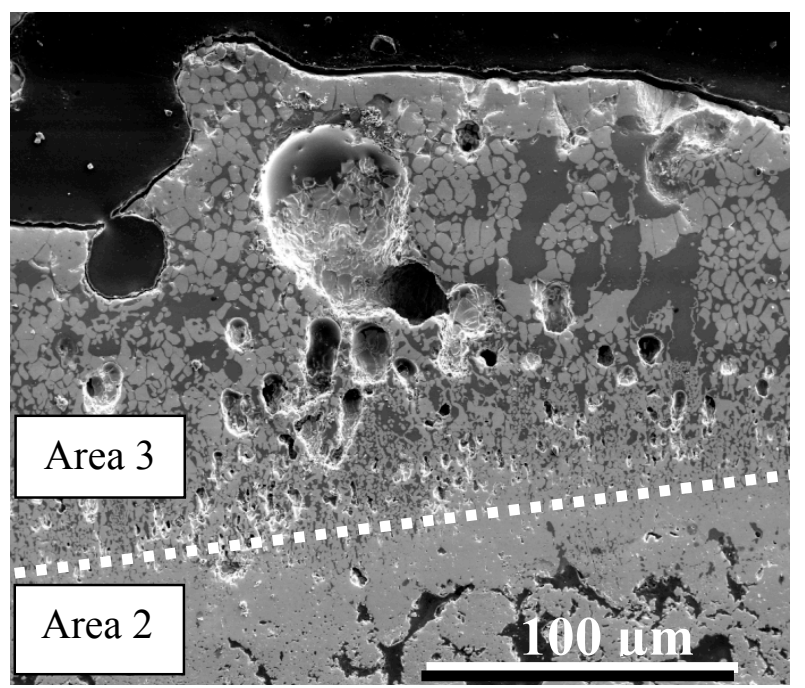

Fig. 10: SE SEM observation of porosities at the surface of the oxidized sample A.

A particularity of the Area 3 is Hf containing recrystallized parts forming dendrites, more visible in important glassy phase volume. Dendrites are exposed in Fig. ${ }^{\circ} 11$. The Fig. ${ }^{\circ} 11$ (a) corresponds to an axial view of dendrites. Fig. ${ }^{\circ} 11$ (b) corresponds to a perpendicular view of the dendrites.

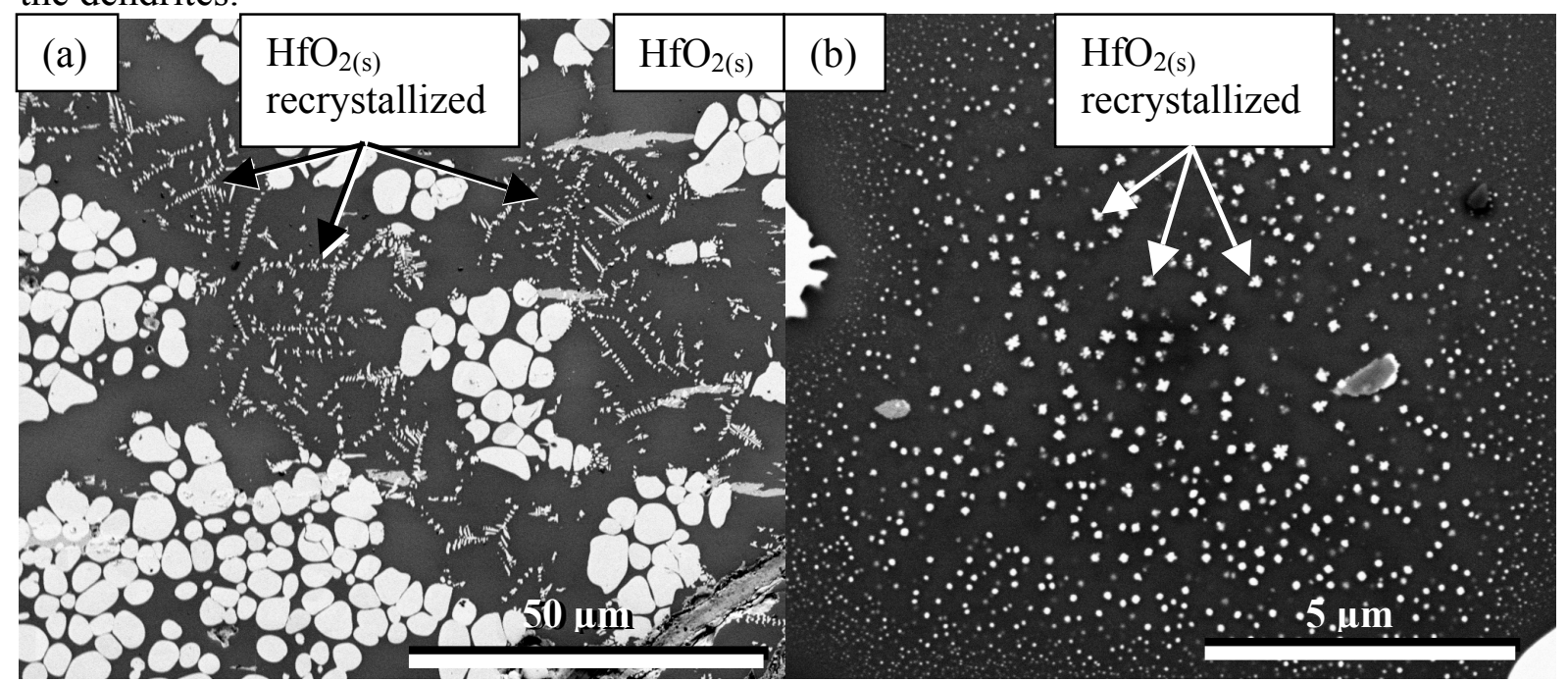

Fig. ${ }^{\circ} 11$ : View of area 3 containing dendrites made by recrystallization of a $\mathrm{Hf}$ containing compound. Fig. ${ }^{\circ} 11$ (a) corresponds to an axial view of dendrites. Fig. ${ }^{\circ} 11$ (b) corresponds to a perpendicular view of dendrites.

Raman spectroscopy analyses results are presented in Fig. ${ }^{\circ} 12$. A spectrum is first realized on a $\mathrm{HfO}_{2(\mathrm{~s})}$ skeleton and compare to the spectrum exposed by S. N. Tkachev [13] A second spectrum is realized on the phase composed by the glassy phase and dendrites. Results are exposed in Fig. ${ }^{\circ} 12$. The spectrum shows an amorphous part corresponding to the glassy phase and a crystallized part corresponding to $\mathrm{HfO}_{2(\mathrm{~s})}$ spectrum. Consequently, the Hf containing recrystallized component is $\mathrm{HfO}_{2(\mathrm{~s})}$ 


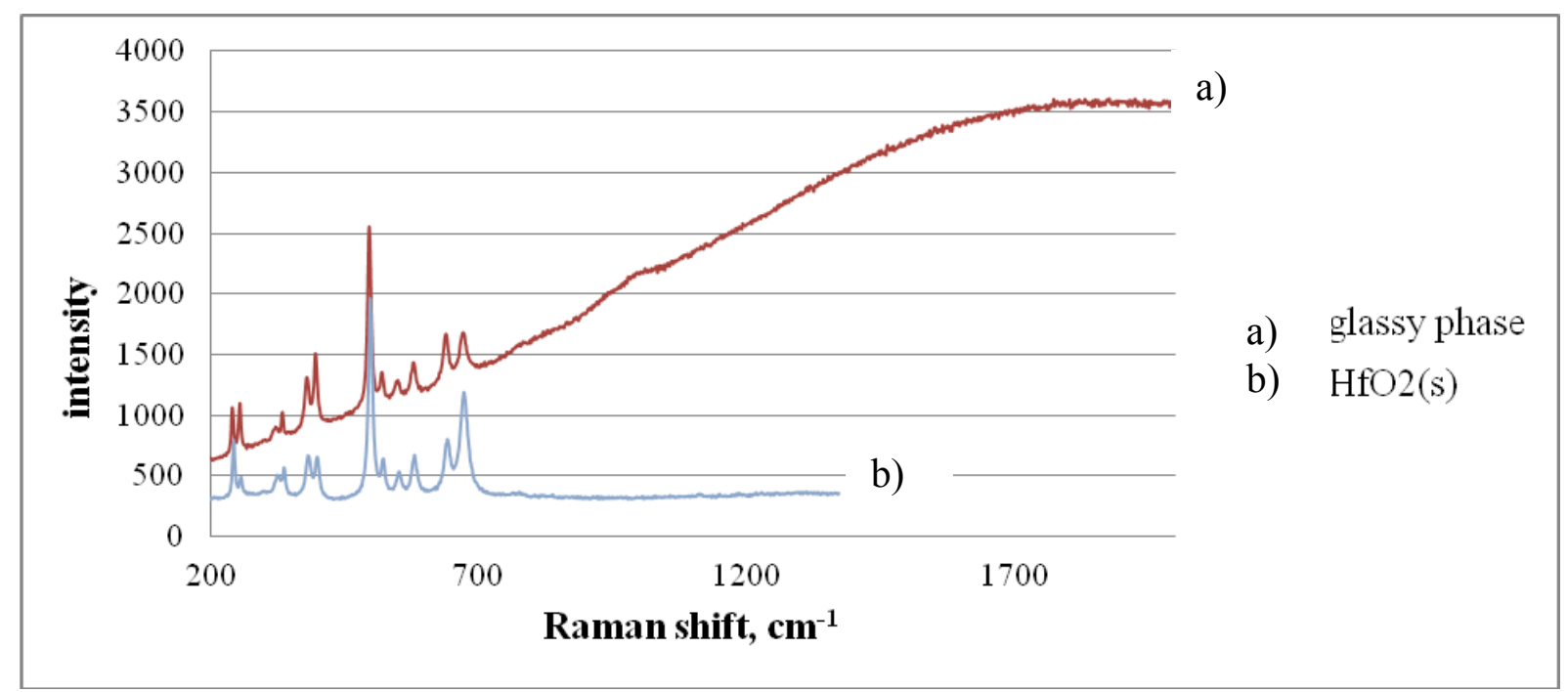

Figure 12: Raman spectrum. a) Curve corresponding to glassy phase with dendrites analyses. b) Curve corresponding to $\mathrm{HfO} 2(\mathrm{~s})$ in area 3 formed during oxidation analyses.

\subsection{CVD Coatings on $\mathrm{C} / \mathrm{C}$ composites}

\subsubsection{Sample B.}

Fig. 13 presents a sample B-type coating over a $\mathrm{C} / \mathrm{C}$ substrate with three layers of $\mathrm{SiC}$ in dark grey and two layers of HfC in light grey. Unlike Fig. 13, sample B has actually a total of ten alternated layers of $\mathrm{HfC}$ and $\mathrm{SiC}$, the coating is $20 \mu \mathrm{m}$ thick (not shown here).

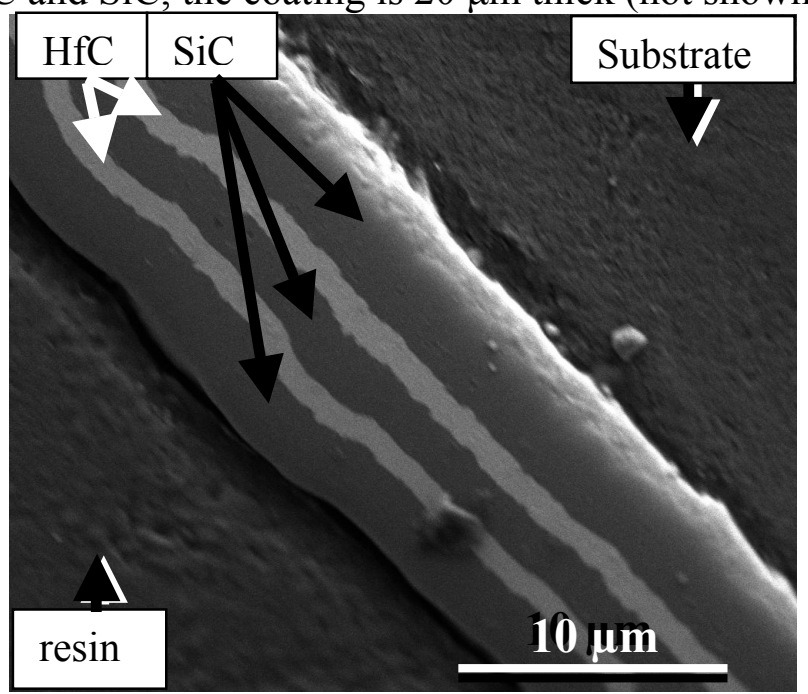

Fig. 13: SE SEM image of a sample B-type coating, made by CVD. This sample consists of a two-dimensional multilayer coating on $\mathrm{C} / \mathrm{C}$ substrate only five layers are shown on this picture.

Fig. 14 presents the microstructure after oxidation at $2000^{\circ} \mathrm{C}$ under air after 200 s of sample B (same oxidation step as sample $\mathrm{A}$ and $\mathrm{C}$ ). Neither residual carbide multilayer coating nor oxide layers are visible. The $\mathrm{C} / \mathrm{C}$ substrate is naked and only slightly damaged at the surface. An oxide scale has certainty protected this sample. But a spelling of the superficial oxidized layer occurs 


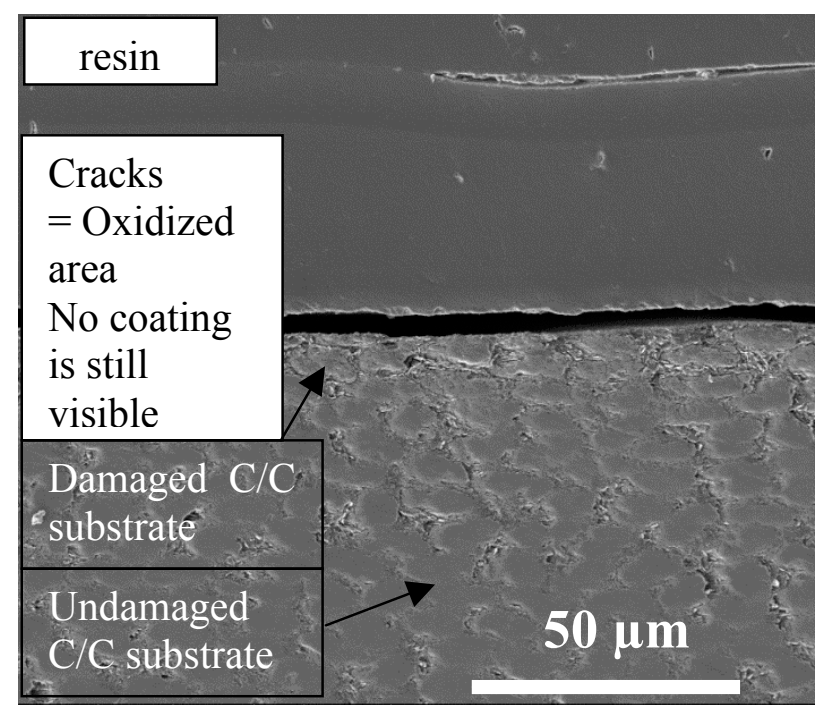

Fig. 14: SE SEM picture of a sample initially coated with a two-dimensional coating, like sample $\mathrm{B}$, after oxidation in air at $2050^{\circ} \mathrm{C}$. No coating is still visible it delaminated.

\subsubsection{Sample C.}

Fig. 15 presents an example of sample $\mathrm{C}$ before oxidation with its 10 layers coating. The coating is $40 \mu \mathrm{m}$ thick. Two parts are visible, the five first layers forming the threedimensional structure where the sub-layers are concentrically arranged around SiC whiskers. This structure was detailed on the paragraph 2.2 multilayer coating made by CVD. Over this structure a two-dimensional part made of five layers is visible [11].

Fig. 15: SE SEM images of sample $C$ before oxidation.

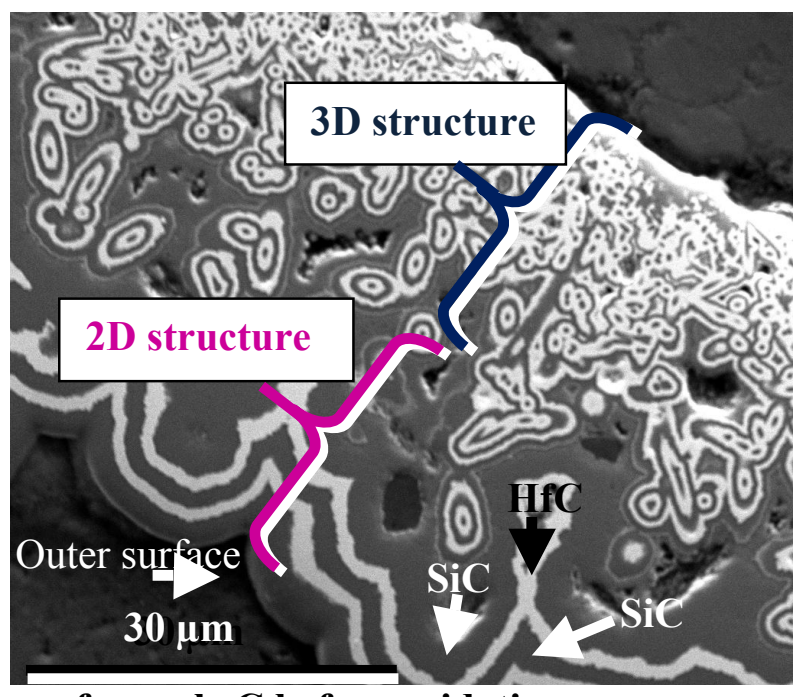

After oxidation (following the path exhibited in paragraph 2.3 oxidation test) of sample $\mathrm{C}$, an oxidized coating layers are still observed on the $\mathrm{C} / \mathrm{C}$ (Fig. 16). Fig. 16 a) presents the center of the sample surface, where the coating has been most severely oxidized. Wide cracks have been filled with mounting resin. At the outer surface, a $\mathrm{Si}_{\mathrm{x}} \mathrm{O}_{\mathrm{y}} \mathrm{Hf}_{\mathrm{z}}$ glass is evidenced by chemical analysis, as in sample A. Holes created by gas released are also observed. The initial two-dimensional $(\mathrm{SiC} / \mathrm{HfC})_{\mathrm{n}}$ multilayer coatings have been replaced by some $\mathrm{HfO}_{2(\mathrm{~s})}$ structure broken into disorganized pieces. SiC seems to have disappeared; only some residuals parts are visible in Fig. 16. The three-dimensional and undamaged structure of the coating is still visible close to the substrate. In place of the initial three-dimensional coating close to the 
substrate, the oxide mixture of $\mathrm{HfO}_{2(\mathrm{~s})}$ and $\mathrm{Si}_{\mathrm{x}} \mathrm{O}_{\mathrm{y}} \mathrm{Hf}_{\mathrm{z}}$ is also found but with a more refined microstructure. The carbon/carbon substrate has begun to be locally damaged.

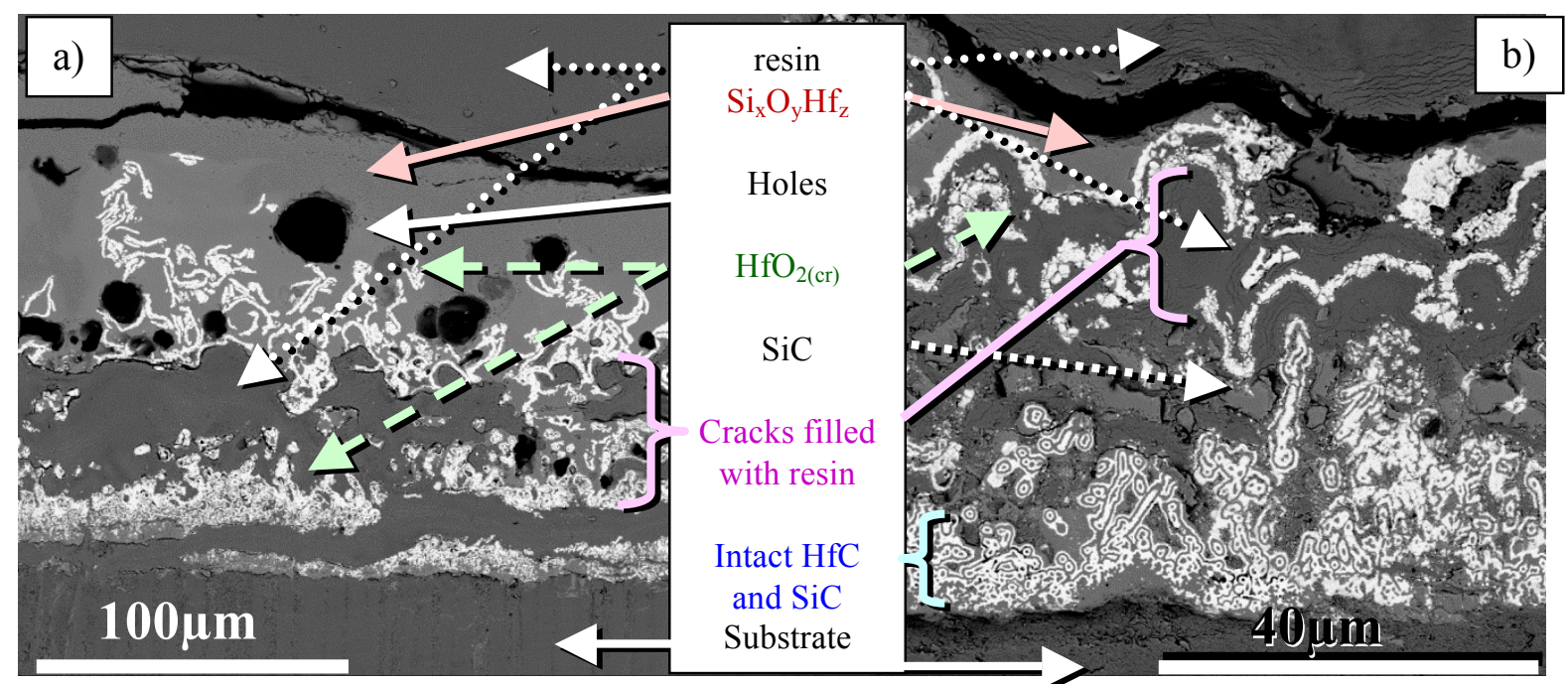

Fig. 16: BSE SEM images of the center (a) and the side (far from the spot impact) (b) of sample $\mathrm{C}$ exposed to oxidation in air at $2000^{\circ} \mathrm{C}$.

Fig. $16 \mathrm{~b}$ ) presents the side of the sample, where the coating is less damaged. The different behavior between the side and the centre of the sample surface can be explained by the temperature gradient. Under the outer $\mathrm{Si}_{\mathrm{x}} \mathrm{O}_{\mathrm{y}} \mathrm{Hf}_{\mathrm{z}}$ glass layer, evidenced by chemical analysis, $\mathrm{HfO}_{2(\mathrm{~s})}$ sub-layers are found separated by wide cracks filled with mounting resin. This feature evidences that $\mathrm{SiC}$ layers have undergone an active oxidation. The free spaces created becomes delamination zone between the sub-layers. Although cracked in some places, the oxide layers are more continuous than in Fig. 16 a) and retain the original shape of the twodimensional HfC sub-layers that they replace. Some residuals SiC sub-layers are still present. Close to the substrate, the initial three-dimensional multilayer carbide coating is observed with its undamaged structure. The inner part of the coating is thus non-oxidized, $\mathrm{SiC}$ and $\mathrm{HfC}$ layers being intact.

From the studies of these samples, an oxidation mechanism can be proposed. The species found in sample $\mathrm{C}$ are the same as in sample A after oxidation. The hypothesis is that the mechanism of the monolithic sample oxidation and the one of the three-dimensional coating oxidation are very similar and involve the same chemical reactions.

\section{Discussion:}

\subsection{Mechanism based on the monolithic sample behavior}

Pure HfC begins to be oxidized above $500^{\circ} \mathrm{C}$ [9]. But in this study, $\mathrm{HfC}$ is combined with $\mathrm{SiC}$. From $500^{\circ} \mathrm{C}$ to $1500^{\circ} \mathrm{C}, \mathrm{SiC}$ is oxidized to $\mathrm{SiO}_{2}$ which is supposed to significantly protect $\mathrm{HfC}$ from oxidation because $\mathrm{SiO}_{2(\mathrm{~s})}$ is the most effective oxygen barrier coating below $1500^{\circ} \mathrm{C}$ [1]. From room temperature to $1650^{\circ} \mathrm{C}$ the oxidation temperature rises in less than 100 s which can be considered as very fast. Consequently, it is admitted that the $\mathrm{SiO}_{2}$ first layers produced by $\mathrm{SiC}$ oxidation still protect $\mathrm{HfC}$ from $\mathrm{O}_{2}$ which did not have the time to diffuse through the $\mathrm{SiO}_{2}$ layer. 
Above $1700^{\circ} \mathrm{C}$, in agreement with the $\mathrm{HfO}_{2}-\mathrm{SiO}_{2}$ binary diagram (Fig. 17) [14] [15], the suggested mechanism of sample A oxidation, presented in Fig. 18, consists of 3 steps which, once initiated, can take place simultaneously.

First, HfC and SiC are oxidized according to reactions R1 and R4 near the outer surface and according to reactions $\mathrm{R} 2$ and $\mathrm{R} 5$ deeper where oxygen partial pressure is lower. These reactions release gases $\left(\mathrm{CO}_{(\mathrm{g})}, \mathrm{CO}_{2(\mathrm{~g})}\right.$ and $\left.\mathrm{SiO}_{(\mathrm{g})}\right)$. At the surface, $\mathrm{SiO}_{(\mathrm{g})}$ released from the inner part of the sample is oxidized according to R3 to form a condensed and liquid layer of $\mathrm{SiO}_{2(1)}$ because of higher oxygen partial pressure [16]. This liquid tends to seal the pores and cracks of the outer scale. Moreover $\mathrm{CO}_{(\mathrm{g})}$ and $\mathrm{CO}_{2(\mathrm{~g})}$ create bubbles in the outer liquid oxide layer as shown in Fig.10 and Fig.16 a) (where holes are observed) and cracks in the $\mathrm{HfO}_{2(\mathrm{~s})}$ structure in the deeper and outer parts as shown in Fig. 16. The phenomena involved in the deeper part correspond to the formation of area 2 in the schematic representation (Fig. 18).

Finally, $\mathrm{SiO}_{2(1)}$ dissolves a part of $\mathrm{HfO}_{2(\mathrm{~s})}$ and reacts with it to form a hafnium-containing silicate liquid, $\mathrm{Si}_{\mathrm{x}} \mathrm{O}_{\mathrm{y}} \mathrm{Hf}_{\mathrm{z}(\mathrm{l})}$, according to $\mathrm{R} 6$ and the binary diagram of $\mathrm{HfO}_{2}-\mathrm{SiO}_{2}$ that highlights the coexistence at $2000^{\circ} \mathrm{C}$ of $\mathrm{HfO}_{2(\mathrm{~s})}$ with a silicon-rich liquid $\left(\mathrm{SiO}_{2} 90 \%{ }_{\mathrm{mol}}\right.$; $\mathrm{HfO}_{2}$ $10 \%$ mol.) (Fig. 18) [14] [15]. The liquid results in a $\mathrm{Si}_{\mathrm{x}} \mathrm{O}_{\mathrm{y}} \mathrm{Hf}_{\mathrm{z}}$ hafnium-containing silicate glass after quenching leading to the formation of area 3 with the remaining $\mathrm{HfO}_{2(\mathrm{~s})}$ that was not dissolved by $\mathrm{SiO}_{2(1)}$ and forms a skeleton. Hence, hafnium is always found by EDS analyses. But, contrary to Wang et al. [7] the $\mathrm{HfSiO}_{4}$ glassy phase has not been observed here. This glassy phase is formed during a longer oxidation time at lower temperature $\left(1500^{\circ} \mathrm{C}\right.$ and 66 hours).

However analyses of recrystallised dendrites shows that they are composed by $\mathrm{HfO}_{2(\mathrm{~s})}$. The quantity of $\mathrm{Hf}$ inside glassy phase is inferior to $5 \%$ atomic. It corresponds in the binary diagram, Fig. ${ }^{\circ} 18$, to a mixt $\mathrm{HfO}_{2}-\mathrm{SiO}_{2}$ with respectively 5 and $95 \%$ atomic at least. At $2000^{\circ} \mathrm{C}$ this composition is completely liquid and corresponds to $\mathrm{Si}_{\mathrm{x}} \mathrm{O}_{\mathrm{y}} \mathrm{Hf}_{\mathrm{z}}$. When the oxidation test is finished the glassy phase is cooled and HfO2(s) recrystallized.

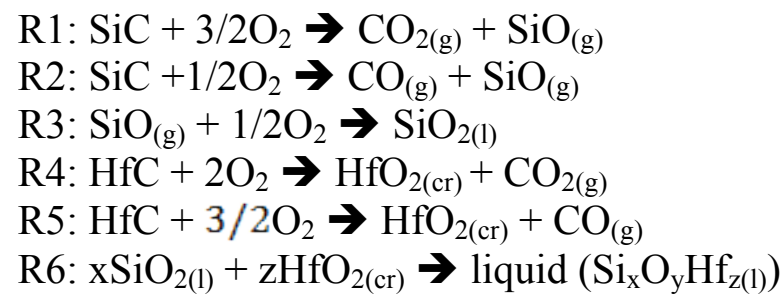




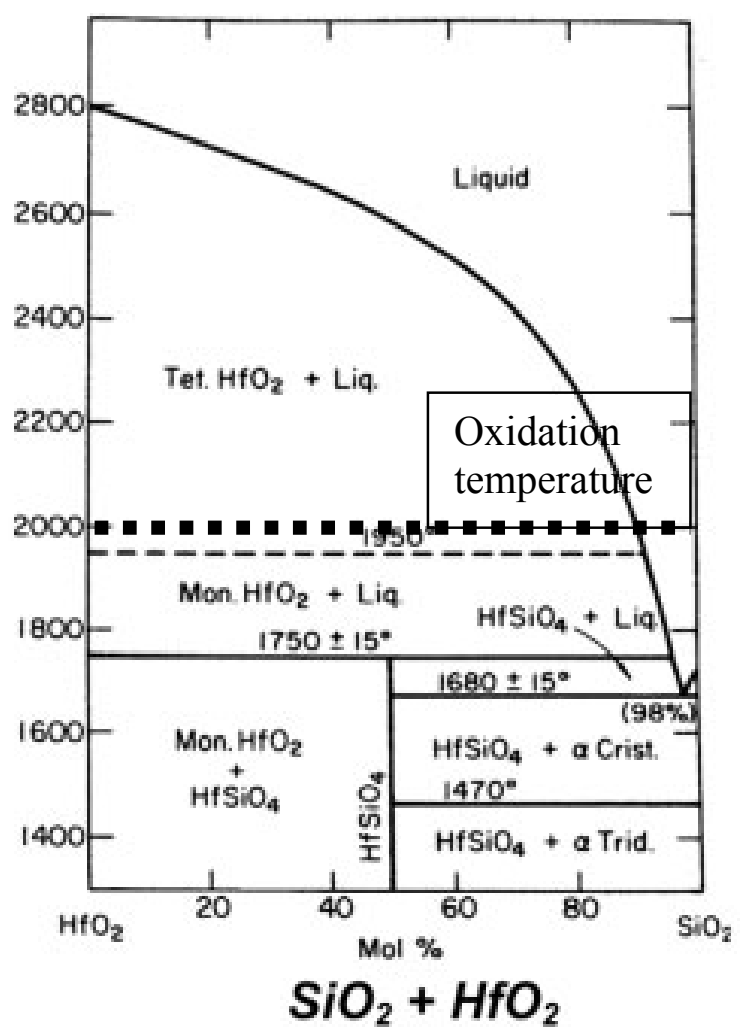

Fig. 17: $\mathrm{HfO}_{2}-\mathrm{SiO}_{2}$ binary diagram [13]

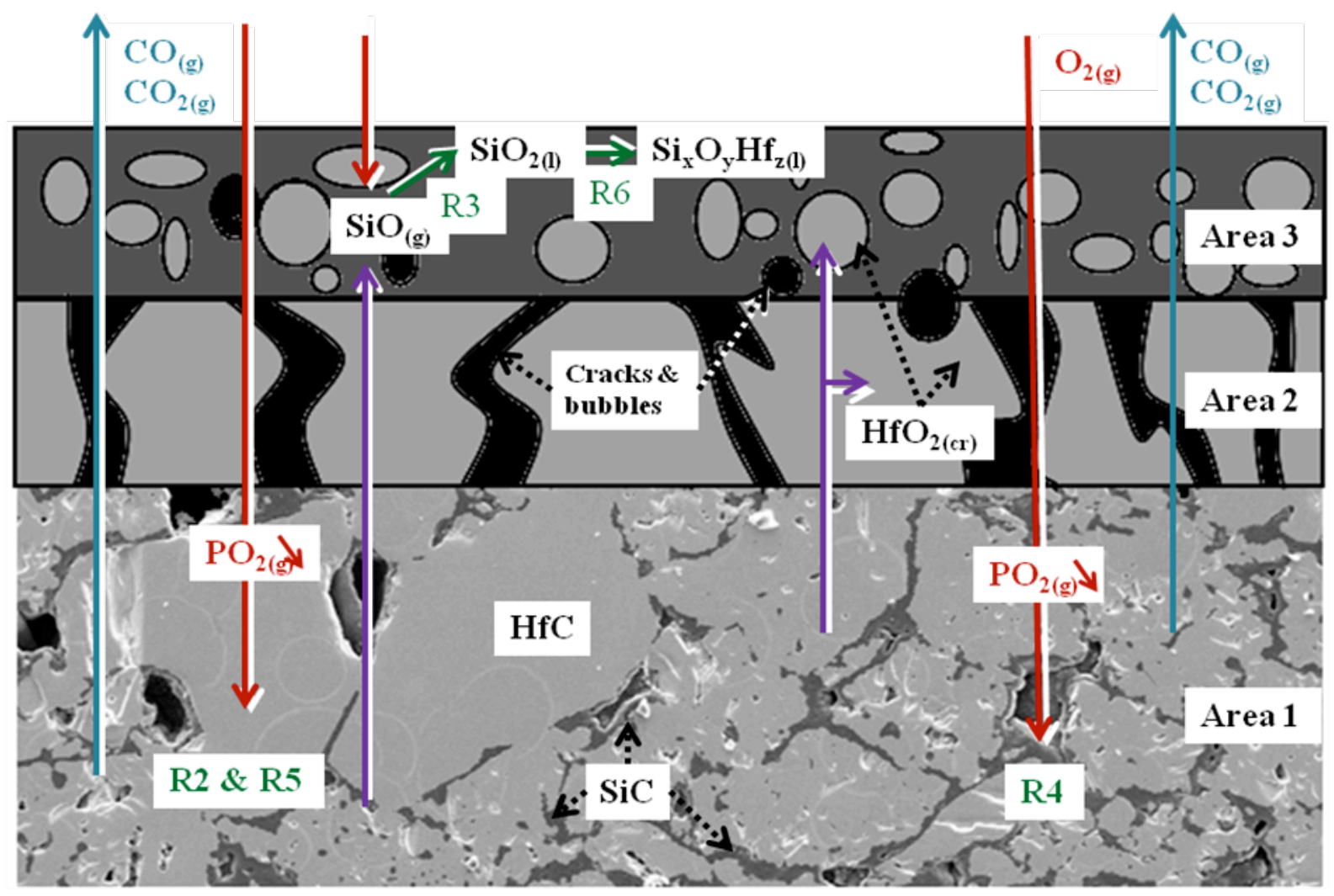

Fig. 18: schematic representation of the oxidation mechanism of the monolithic sample. 
From this, it is proposed that the effective protection against oxidation is based on the formation of the $\mathrm{Si}_{\mathrm{x}} \mathrm{O}_{\mathrm{y}} \mathrm{Hf}_{\mathrm{z}}$ hafnium-containing silicate liquid combined with the $\mathrm{HfO}_{2 \text { (cr) }}$ skeleton.

As explained by Vogel, when a group 4 element, like hafnium, is added to $\mathrm{SiO}_{2(1)}$ the tendency to phase separation and immiscibility rises and so the viscosity $\eta$ increases [17]. Opeka et al. [16] made the link between Vogel and the Stokes-Einstein relationship which shows that the oxygen diffusion coefficient through the liquid oxide is inversely proportional to the viscosity. Consequently, by adding Hafnium, the oxygen diffusion coefficient decreases and next sub-layers are better protected from oxidation than with pure $\mathrm{SiO}_{2(1)}$. These authors were the first to develop the concept of "phase separation as a controlling factor in the oxidation protection".

Furthermore, the $\mathrm{HfO}_{2 \text { (cr) }}$ skeleton acts as a grip holding the liquid $\mathrm{Si}_{\mathrm{x}} \mathrm{O}_{\mathrm{y}} \mathrm{Hf}_{\mathrm{z}}$ in place during oxidation and so helps to protect next layers from further oxidation.

Theses two points take a part in coating oxidation protective role.

\subsection{Extrapolation of the mechanism for CVD samples}

The behavior under oxidation of the monolithic sample $\mathrm{A}$ is used as a basis that can be extrapolated to the oxidation mechanism of CVD coated samples B and C.

In both samples $\mathrm{B}$ and $\mathrm{C}$, the five exposed outer layers are two-dimensional. First, the most outer layer, made of $\mathrm{SiC}$, is oxidized below $1500^{\circ} \mathrm{C}$ to form $\mathrm{SiO}_{2(1)}$ according to $\mathrm{R} 1$, the oxidation of $\mathrm{SiC}$ being passive [8]. When the temperature increases, the $\mathrm{SiC}$ oxidation becomes active and the $\mathrm{SiO}_{2(1)}$ layer is ruptured by the produced gases. In the same time, the oxygen diffuses through the ruptured $\mathrm{SiO}_{2(1)}$ scale and reaches the deeper carbide sub-layers.

The oxidation mechanism should be then similar to the monolithic sample oxidation mechanism explained in paragraph 4.1 Mechanism based on the monolithic sample behavior. But as $\mathrm{HfC}$ and $\mathrm{SiC}$ have different coefficients of thermal expansion, the temperature increase induces delamination and cracks between the $\mathrm{C} / \mathrm{C}$ substrate and the multilayer coating.

In the case of sample $\mathrm{C}$, the initial deeper three-dimensional structure part is composed of concentric and interlocked carbide sub-layers that give a mechanical grip preventing delamination [18]. Silicon and hafnium carbide phases being kept in contact with each other; the oxidation mechanism can occur as described above for the monolithic sample A and so protects more effectively the $\mathrm{C} / \mathrm{C}$ substrate.

\section{Conclusion}

A new protection against oxidation at very high temperature composed of hafnium and silicon carbides was realized by two synthesis ways. Its behavior under oxidation was studied with an arc image furnace. After oxidation under air at $2000^{\circ} \mathrm{C}$ the microstructure and composition of samples were characterized and a mechanism was proposed. Finally, the influence of the coating structure was studied and the advantage of the three-dimensional structure over the two-dimensional multilayer structure was highlighted. The oxidation mechanism took into account six reactions, two corresponding to $\mathrm{SiC}$ oxidation, two to $\mathrm{HfC}$ oxidation, one to an oxidation of $\mathrm{SiO}_{(\mathrm{g})}$ when the oxygen partial pressure increases at the sample surface, and one between $\mathrm{HfO}_{2(\mathrm{~s})}$ and $\mathrm{SiO}_{2(\mathrm{l})}$ forming a hafnium-containing silicate glass in addition to the unreacted $\mathrm{HfO}_{2(\mathrm{~s})}$, in agreement with the $\mathrm{HfO}_{2}-\mathrm{SiO}_{2}$ phase diagram.

The resistance against oxidation of samples mainly comes from the $\mathrm{Si}_{\mathrm{x}} \mathrm{O}_{\mathrm{y}} \mathrm{Hf}_{\mathrm{z}}$ liquid phase which limits the oxygen diffusion better than pure $\mathrm{SiO}_{2}$. In addition, the three-dimensional structure has three advantages. It allows the formation of $\mathrm{HfO}_{2(\mathrm{~s})}$ skeleton that acts as a grip holding the $\mathrm{Si}_{\mathrm{x}} \mathrm{O}_{\mathrm{y}} \mathrm{Hf}_{\mathrm{z}}$ liquid in place (i); consequently it cannot be easily removed by gas flux. 
The three-dimensional structure with initial interlocked carbide sub-layers gives a mechanical grip between the $\mathrm{C} / \mathrm{C}$ composite and the multilayer coating (ii). Moreover, it increases the exchange surface between the chemical compounds (iii). Complementary works are in progress specifically to assess the potential of other combinations of refractory carbides like tantalum carbide.

\section{Acknowledgment}

This work was support by the "Alternative Energies and Atomic Energy Commission" (CEA). We thank M. Lahaye of "the Center for characterization of advanced materials for chemical" (CeCAMA) for characterization of the layers and Prof. F. Rebillat to give us tracks to follow.

\section{References}

[1] McKee DW. Oxidation Protection of Carbon Materials. In: Thrower PA, editor. Chemistry and physics of carbon, vol. 23. New York: Marcel Dekker; 1991. p. 173-232.

[2] Paul A, Jayaseelan DD, Venugopal S, Zapata-Solvas E, Binner J, Vaidhyanathan B,Heaton A, Brown P, Lee WE. UHTC composites for hypersonic applications. Am Ceram Soc Bull 2012;91(1):22-8.(http://hdl.handle.net/2134/9676)

[3] Clougherty EV, Pober RL, Kaufman L. Synthesis of Oxidation Resistant Metal Diboride Composites. Trans Metall Soc AIME 1968;242:1077-82.

[4] Parthasarathy TA, Rapp RA, Opeka M, Kerans RJ. A model for the oxidation of $\mathrm{ZrB}_{2}$, $\mathrm{HfB}_{2}$ and $\mathrm{TiB}_{2}$. Acta mater 2007;55:5999-6010. http://dx.doi.org/10.1016/j.actamat.2007.07.027

[5] Wunder V, Popovska N, Wegner A, Emig G. Arnold W. Multilayer coatings on CFC composites for high-temperature applications. Surf Coat Tech 1998;100-101:329-32 http://dx.doi.org/10.1016/S0257-8972(97)00643-9

[6] Baklanova NI, Zima TM, Boronin AI, Kosheev SV, Titov AT, Isaeva N.V, Grashenkov DV, Solntesev SS. Protective ceramic multilayer coatings for carbon fibers. Surf Coat Tech 2006;201:2313-19. http://dx.doi.org/10.1016/j.surfcoat.2006.03.046

[7] Wang Y, Li H, Fu Q, Wu H, Yao D, Li H, SiC/HfC/SiC ablation resistant coating for Carbon/Carbon composites; Surf. Coat. Tech. 2012, 206, 3883-3887 http://dx.doi.org/10.1016/j.surfcoat.2012.03.039

[8] Strife JR, Sbeehan JE, Ceramic coating for carbon-carbon composites, Am. Ceram. Soc. Bull.1988, 67 (2) 369-374

[9] Shimada S, Inagaki M, Matsui K. Oxidation Kinetics of Hafnium Carbide in the temperature Range of $480^{\circ} \mathrm{C}$ to $600^{\circ} \mathrm{C}$. J Am Ceram Soc 1992;75(10):2671-78. http://dx.doi.org/10.1111/j.1151-2916.1992.tb05487.x 
[10] A. Allemand, L. Bianchi, Y. Le Petitcorps, O. Szwedek, « Procédé pour revêtir une pièce d'un revêtement de protection contre l'oxydation » French patent, 2010-10-25, patent application FR2966455, N ${ }^{\circ}$ WO 2012055865.

[11] A. Allemand, O. Szwedek, J. F. Epherre, Y. Le Petitcorps, « Procédé pour revêtir une pièce d'un revêtement de protection contre l'oxydation par une technique de dépôt chimique en phase vapeur, et revêtement et pièce » French patent, 2011-11-25, Patent application $\mathrm{N}^{\circ} 1160815$.

[12] Kaplan R. B. and al.US Pat. 5283109 (1994)

[13] S. N. Tkachev,M. H. Manghnani, A. Niilisk, J. Aarik, H. Mändar; Raman and Brillouin scattering spectroscopy studies of atomic layer-deposited $\mathrm{ZrO}_{2}$ and $\mathrm{HfO}_{2}$ thin film;Spectrochimica Acta Part A: Molecular and Biomolecular Spectroscopy, Vol 61, Issue 10, 2005, p 2434-2438.

http://dx.doi.org/10.1016/j.saa.2005.02.025

[14] Levin EM, Robbins CR, McMurdie HF. Phase Diagrams for Ceramists. Am. Ceram. Soc., Columbus, Ohio, USA, 1964.

[15] Shin D, Arroyave R, Liu Z. Thermodynamic modeling of the Hf-Si-O system, Calphad 2006;30(4):375-86 http://dx.doi.org/10.1016/j.calphad.2006.08.006

[16] Opeka MM, Talmy IG, Zaykoski JA. Oxidation-based materials selection for $2000^{\circ} \mathrm{C}+$ hypersonic aerosurfaces: Theoretical consideration and historical experience. J Mater Sci 2004;39:5887-904 http://dx.doi.org/10.1023/B:JMSC.0000041686.21788.77

[17] Vogel W, Glass Chemistry. 2nd ed. (Springer-Verlag, NewYork) 1994

[18] Y. Chu, Q. Fu, H. Li, H. Wu, K. Li, J. Tao, Q. Lei ; SiC coating toughened by SiC nanowires to protect $\mathrm{C} / \mathrm{C}$ composites against oxidation, Ceramics international, issue 38, 2012, 189-194.

http://dx.doi.org/10.1016/j.ceramint.2011.05.159, 